\title{
Molecular subtyping and phylogeny of Blastocystis sp. isolated from turkey (Meleagris gallopavo) populations in Penang, Malaysia
}

\author{
Siti Alawiyah, J.A.N. ${ }^{1}$, Rauff-Adedotun, A.A. ${ }^{1}$, Aishah, S. $^{1}$, Rusydi Abdul Hafiz, R. $^{2}$, Zary Shariman, Y., \\ Farah Haziqah, M.T. ${ }^{1}{ }^{*}$
}

${ }^{1}$ School of Biological Sciences, Universiti Sains Malaysia, 11800 USM, Penang, Malaysia

${ }^{2}$ Department of Veterinary Services, Jalan Bukit Tengah, 14000 Bukit Mertajam, Penang, Malaysia

*Corresponding author: farahhaziqah@usm.my

\section{ARTICLE HISTORY}

Received: 17 August 2021

Revised: 4 December 2021

Accepted: 4 December 2021

Published: 31 December 2021

\begin{abstract}
Most poultry farms in Malaysia preferred rearing chickens either for eggs or/and meat than turkeys. This is due to several challenges such as parasitic load and heat stress in rearing turkey. Blastocystis is one of the most common protozoan parasites infecting poultry. As no study was conducted on Blastocystis infection in turkey in Malaysia, this study aims to determine the current status, the morphological characteristics and subtyping of Blastocystis from turkey reared either in closed house or free-range system in Penang, Malaysia. It was found that the prevalence of Blastocystis sp. infection in turkeys were moderately high with $41.6 \%(25 / 60)$ in the closed house and $45.0 \%$ (45/100) in free-range system as infection was higher in the female turkeys with no gastrointestinal signs and symptoms. Vacuolar form was the most common form found in the in vitro culture ranged between 5 to $20 \mu \mathrm{m}$ in diameter with a rough surface coat and undulating cell surface viewed under the scanning electron microscope. Meanwhile, the ultrastructure of the cells from turkey isolates were varies with partially expanded electron-opaque vacuoles to electron-dense in fully distended vacuoles. Interestingly, sequence analysis for 30 positive Blastocystis isolates from turkeys revealed one subtypes with three alleles namely, ST7 allele $99(73.4 \%, n=22)$, ST7 allele 100 $(23.3 \%, n=7)$ and ST7 allele $101(3.3 \%, n=1)$. Findings from this study added to our understanding on Blastocystis infection in turkey production.
\end{abstract}

Keywords: Blastocystis; Malaysia; Penang; protozoan; turkey.

\section{INTRODUCTION}

Wild turkeys are huge, sexually dimorphic fowls with long feet, wide and curved tails, elongated necks and small heads (Miller, 2018). Wild turkey (Meleagris gallopavo) is associated with the other members in the order Galliformes, family Meleagridae and genus Meleagris. Wild turkeys are very adjustable in various conditions, capable to live in warm environments as well as to some countries that are frequently blanketed with snow. The adult males, known as tom or gobblers, weigh from 10 to $15 \mathrm{~kg}$ throughout their range depends on the type of breeds. The adult females, known as hens, commonly do not surpass $10 \mathrm{~kg}$, with the typical weight from 6 to $9 \mathrm{~kg}$ (Cathey et al., 2007). In Malaysia, turkeys are reared for many purposes such as poultry meat as well as a hobby. Turkeys are considered expensive and have a high demand especially during festive season such as Christmas Eve and Deepavali.

The turkey's usual behaviors are to forage food on soil, therefore, there are numerous types of organisms as well as intermediate hosts that can cause the endoparasites infection in turkeys as they are omnivorous, they have a wideranging diet. Mohammad Zarith et al. (2017) stated that studies on the dispersion of parasitic infection in turkeys particularly in Malaysia is still scarce which probably due to Malaysian preference to eat more chicken than turkey, making study on turkey diseases economically insignificant.

Generally, turkeys are having some issues to several parasitic diseases caused by protozoan parasites. Protozoa are single-celled organisms that can be commensals or parasitic in nature. There are certain species of parasitic protozoan which include in the medical importance worldwide. In turkey population, the most common species of parasitic protozoan encountered were Eimeria spp. which cause coccidiosis (Sharman et al., 2010) and Histomonas meleagridis, the source of Blackhead disease (histosomiasis). Other protozoan which may also infect turkeys include Hexamita meleagridis (Hexamitiasis), Trichomonas gallinae (trichomoniasis) and Cochlosoma anatis (cochlosomiasis) (Hauck \& Hafez, 2012). Apart from that, a neglected zoonotic protozoan known as Blastocystis sp. was also been found in 
turkeys (Lee, 1970; Yamada et al., 1987; Belova \& Kostenko, 1990; Belova, 1992a; Mokhtar \& Youssef, 2018).

Blastocystis sp. is a common, non-flagellated, anaerobic stramenopiles (Gentekaki et al., 2017) that inhabits the gastrointestinal tracts in many humans and various animals particularly poultry (Mokhtar \& Youssef, 2018). Blastocystis exists in four different morphological form namely, vacuolar, granular, amoeboid and cyst form (Tan, 2008). The most common mode of reproduction is binary fission (Adao \& Rivera, 2018) in which cyst is the infective form that accountable in the transmission. The main transmission mode of this protozoan is through the faecal-oral pathway via drinking untreated water and/or poor sanitary conditions.

The occurrence of this organism has been perceived in a wide diversity of species worldwide. It has a great genetic diversity thus the genotypes were assigned using the subtyping nomenclature (ST) (Rauff-Adedotun et al., 2020). Nomenclature Blastocystis sp. subtypes (STs) ST1-ST9 was first presented in 2007 (Rauff-Adedotun et al., 2020), after many of subtypes were proposed recently. Starting from the year 2013, new subtypes was recognized which was ST1-ST17 between some hosts (Alfellani et al., 2013; Stensvold \& Clark, 2020). Presently, a total of 29 subtypes have been suggested (RauffAdedotun et al., 2020). However, four subtypes out of 29 subtypes that have been proposed namely, ST18, ST19, ST20 and ST22 was recently under question due to the probability that they were generated from memento consequently their quixotic emergence (Stensvold \& Clark, 2020). The enduring 25 subtypes which include ST1-ST17, ST21, ST23-ST29 have encountered the existing suggested standards for distinctive subtype nominations (Maloney \& Santin, 2021). Additionally, ten subtypes, ST1-ST9 and ST12 have been revealed in humans, with fluctuating stages of existence (Greige et al., 2019) later the possibility of zoonotic transmission will occur (Clark et al., 2013; Stensvold et al., 2020).

The most recent study on Blastocystis in poultry by Greige et al. (2018) reported that the avian samples specifically from chickens in Lebanon were subtyped and fitted to any ST6 or ST7, with a great majority belongs to ST6. Surprisingly, this subtype also been detected among the chicken handlers which affirmed that there was zoonotic transmission of this ST as those individuals were frequently in a direct contact with the chickens. Meanwhile, Mokhtar \& Youssef (2018) reported the occurrence of ST1, the zoonotic subtypes with a prevalence of $7.8 \%$ in poultry species among the chicken, ducks, geese and turkeys isolates in Egypt. It was also been found in humans having similar ST with the animals that they handle. Besides, the study also reported the occurrence of ST7 and ST6 in both turkeys and chickens in which both subtypes were represented as avian-adapted STs.

Most of the previous studies on Blastocystis in poultry were concentrated on Blastocystis in domestic chickens (Stensvold et al., 2009; Alfellani et al., 2013; Ramirez et al., 2014; Greige et al., 2018; Mokhtar \& Youssef, 2018; Wang et al., 2018; Deng et al., 2019; Rauff-Adedotun et al., 2020; Maloney et al., 2021), quails (Maloney et al., 2021), ducks (Maloney et al., 2020; Rauff-Adedotun et al., 2020; Fahim et al., 2021; Maloney et al., 2021) and ostriches (Chandrasekaran et al., 2014; Maloney et al., 2020; Rauff-Adedotun et al., 2020; Deng et al., 2021; Rudzinska et al., 2021; Zhang et al., 2021). As there are very limited study in turkey population worldwide (Lee, 1970; Belova, 1992a; Noel et al., 2003; Sreekumar et al., 2014; Mokhtar \& Youssef, 2018; Maloney et al., 2020) and none was conducted in Malaysia, therefore, this study will help to provide a baseline study on this neglected zoonotic protozoan parasite infection in turkey population mainly in the northern region of Peninsular Malaysia.

\section{MATERIALS AND METHODS}

\section{Ethical approval}

All animals used in this study were handled according to Animal Ethics and USM Institutional Animal Care and Use Committee (USM IACUC), Universiti Sains Malaysia. Written permission was obtained from the authorities of Department of Veterinary Services as sampling activities were conducted in privately-owned and protected turkey farms.

\section{Sampling sites}

This study was conducted in the Seberang Perai, Penang (Latitude: $5.3700^{\circ} \mathrm{N}$ and Longitude: $100.4139^{\circ} \mathrm{E}$ ) as almost $50 \%$ of farmers reared turkey in this area. Sites were chosen based on types of turkey rearing which was closed house system and free-range system. Sampling activities were conducted on a closed house located at Department of Veterinary Services Penang, Bukit Tengah and several selected backyard farms at Tasek Gelugor, Kubang Menerong and Kepala Batas, Penang.

\section{Study population}

By adopting convenience sampling method (Dornyei, 2007; Etikan et al., 2016), a total of 160 turkeys consisted of freerange and closed house reared turkeys which involved 90 males and 70 females were examined for Blastocystis sp.

The closed house turkeys comprised of commercial broilers that reared specifically for meat. In the closed house, the turkey's reared were the White Holland turkey. They were kept indoors, secluded, retained with controlled temperature and have a good ventilation. Besides, wood shavings were commonly used as deep litter or floor systems with slatted floor. The turkeys were reared by the integrated federal government authorities of Department of Veterinary Services Penang in which the adult female turkey sold to the farmers as an initiative programme from the government. There were 60 faecal turkey samples collected from the closed house involved 20 males and 40 females screened for Blastocystis sp.

The turkeys consisting of free-range turkeys were frequently seen in countryside locations where old-style poultry production was practiced. The turkeys reared breed namely, Black turkey and White Holland that were partially confined and allow to scavenge for food freely and return periodically to the homestead or barn for water and food sources such as kitchen waste or feed pallet. The turkeys were kept in a small barn with the build of fenced area to protect from the predator, especially in the night-time. In this study, 100 faecal turkey samples were collected from the sampling sites consists of 50 males and 50 females.

\section{In vitro cultivation}

A small amount of each faecal sample was inoculated into a sterile screw-top bottle containing $3 \mathrm{ml}$ of modified Jones' medium supplemented with $10 \%$ heat-activated horse serum. Each sample was incubated vertically at $37^{\circ} \mathrm{C}$ for 24 to 48 hours. Later, a drop of the sediment was examined at $400 \mathrm{x}$ magnification for Blastocystis examination in which positive samples were those with the presence of Blastocystis sp. forms. Positive samples were subsequently maintained by sub-culturing every 2 to 3 days and were then stored at $-20^{\circ} \mathrm{C}$ for molecular characterization.

\section{Microscopy examination}

Smears were carried out from day-3 positive culture samples. Later, these smears were fixed with methanol, stained with $10 \%$ Giemsa and then viewed under light microscope at $400 x$ 
and 1000x magnification for the meticulous observation of morphological characteristics.

Selected day-3 positive culture samples from closed house (B7C) and free-range (FM11) turkey were fixed with $2.5 \%$ glutaraldehyde in $0.1 \mathrm{M}$ sodium cacodylate buffer $(\mathrm{pH}$ 7.3). Phosphate buffered saline (PBS) pH 7.4 were used to wash the contents for three times. The samples were centrifuged for 5 minutes at $3000 \mathrm{rpm}$. $2.5 \%$ glutaraldehyde were used to fix the pelleted cells and post-fixed with $1 \%$ osmium tetroxide. Then, the specimens were mounted on polycarbonate membrane and dehydrated in increasing concentration of ethanol $(30 \%, 50 \%, 70 \%, 90 \%)$. The specimens were critical-point dried with carbon dioxide coated with gold and viewed under a scanning electron microscope (SEM) at Centre for Global Archaeological Research, USM, Penang.

Meanwhile, for transmission electron microscopy sample preparation, phosphate buffered saline (PBS) pH 7.4 were used to wash the contents for three times, centrifuged for 5 minutes at $3000 \mathrm{rpm}$ in which $2.5 \%$ glutaraldehyde were used to fixed the pelleted cells and post-fixed with $1 \%$ osmium tetroxide, $\mathrm{pH} 7.3$ at $4{ }^{\circ} \mathrm{C}$, washed thoroughly with cacodylate buffer and post fixed for 30 minutes in $1 \%$ osmium tetroxide in cacodylate buffer. The fixed cells were dehydrated for 5 minutes in ascending series of ethanol $(30 \%, 50 \%, 70 \%, 90 \%)$ and embedded in epoxy resin. Semithin sections were stained with toluidine blue. Ultrathin sections were cut using an ultramicrotome, contrasted with uranyl acetate and lead citrate and viewed under a transmission electron microscope (TEM) at Electron Microscopy Unit, USM, Penang.

\section{DNA Extraction}

Genomic DNA of Blastocystis sp. was extracted by using Nucleospin ${ }^{\circledR}$ DNA stool extraction kit (Macherey-Nagel, German) according to the manufacturer's protocol. The elution step was carried out using $100 \mu \mathrm{l}$ instead of $200 \mu \mathrm{l}$ in order to increase the concentration of total DNA.

\section{DNA Barcoding}

The Blastocystis-specific sequence of the primers used, BhRDr (GAGCTTTTTAACTGCAACAACG) and the broad-specificity eukaryotic-specific primer, RD5 (ATCTGGTTGATCCTGCCAGT) were used in a single step PCR reaction to amplify $600 \mathrm{bp}$ region of rRNA (Clark, 1997).

Amplification of $2 \mu \mathrm{l}$ genomic DNA was carried out in a $50 \mu \mathrm{l}$ reaction containing $25 \mu \mathrm{l}$ of master mix $1.0 \mu \mathrm{l}$ of $\mathrm{MgCl}$, and $0.5 \mu \mathrm{l}$ of each primer. The thermal cycling parameters were comprised as follows; 30 cycles of 1 min respectively at $94^{\circ} \mathrm{C}, 59^{\circ} \mathrm{C}$, and $72^{\circ} \mathrm{C}$, with an added 2 min final extension (Thermal Cycler Bio-Rad, USA).

The amplification products were then electrophoresed in 1.5\% agarose gels and Tris-Acetate-EDTA (TAE) buffer. Gels were stained with DNA gel stain and visualized using ultraviolet gel documentation system. The DNA fragment size was confirmed using a 100 base pair ladder. PCR products of approximately 600bp were sent to Apical Scientific Sdn. Bhd. for purification and sequencing.

The SSU rDNA sequences were then identified by BLAST analysis in the sequence database at Public Databases for Molecular Typing and Microbial Genome Diversity (PubMLST) (https://pubmlst.org/organisms/blastocystis-spp) sequences generated in this study were deposited in GenBank under the accession number MZ437439-MZ437977.

\section{Sequence alignment and phylogenetic analyses}

Nucleotide sequences were analysed using BioEdit version 7.2. Phylogenetic tree was then constructed with MEGA $X$
Platform x86, x86-64 using neighbour joining p-distance model. The sequences isolate from this study together with other Blastocystis sequences from the GenBank.

The evolutionary history was inferred by using the Maximum Likelihood method and Tamura 3-parameter model (Tamura, 1992). The tree with the highest log likelihood $(-11626.88)$ is shown. Initial tree(s) for the heuristic search were obtained automatically by applying Neighbour-Join and BioNJ algorithms to a matrix of pairwise distances estimated using the Tamura 3 parameter model, and then selecting the topology with superior log likelihood value. The phylogenetic tree was rooted using Proteromonas lacertae as an outgroup. This analysis involved 49 nucleotide sequences. There were a total of 1922 positions in the final dataset. Evolutionary analyses were conducted in MEGA X (Kumar et al., 2018).

\section{Statistical analysis}

Statistical analyses were conducted by using the Statistical Package for the Social Sciences (SPSS) statistics 26.0 software package. Chi-square analysis was carried out to determine the statistical significance of the observed the association between the risk factors (sexes and rearing systems) and Blastocystis sp. infection with a probability value of less than 0.05 was considered statistically significant.

\section{RESULTS}

\section{Prevalence of Blastocystis sp. infection}

Out of the 160 turkeys, a total of $70(43.8 \%)$ turkey faecal samples that were positive for Blastocystis sp. infection (Table 1) in which none of the study animals showed behavioural signs or indication of Blastocystis sp. infection.

The prevalence of Blastocystis sp. infection in turkeys reared in the closed house and free-range system were $41.6 \%$ $(25 / 60)$ and $45 \%(45 / 100)$, respectively (Table 1$)$. It was also found that there was no significant difference $(P>0.05)$ reported between the type of turkey rearing system and Blastocystis sp. infection $(\chi 2=0.169,[\mathrm{df}]=1, P=0.681)$ in this study.

Meanwhile, the prevalence of Blastocystis $\mathrm{sp}$. infection in turkey from closed house was higher in female with $60 \%$ $(12 / 20)$ whereas in male with $32.5 \%(13 / 40)$. As, for the freerange turkeys, the prevalence was also reported higher in female with $56 \%(28 / 50)$ than in male with $34 \%(17 / 50)$ (Table 1). There was a significant difference $(P<0.05)$ reported between the sex of turkeys and Blastocystis sp. infection $(\chi 2=$ 4.149, $[\mathrm{df}]=1, P=0.042$ ) in this study.

\section{Morphological forms}

From the in vitro cultivation of Blastocystis sp. isolates in the turkey faecal sample, the morphology of the Blastocystis sp. obtained were mostly vacuolar form approximately from 5 to

Table 1. Prevalence of Blastocystis sp. infection in two types of farming practices in turkey population

\begin{tabular}{lcc}
\hline Study animals & $\begin{array}{c}\text { No. of faecal } \\
\text { samples }\end{array}$ & $\begin{array}{c}\text { No. of turkeys } \\
\text { infected (\%) }\end{array}$ \\
\hline $\begin{array}{l}\text { Closed-house turkeys } \\
\text { Male } \\
\text { Female }\end{array}$ & 40 & $13(32.5 \%)$ \\
$\begin{array}{l}\text { Free-range turkeys } \\
\text { Male } \\
\text { Female }\end{array}$ & 20 & $12(60 \%)$ \\
\hline Total & 50 & $17(34 \%)$ \\
\hline
\end{tabular}




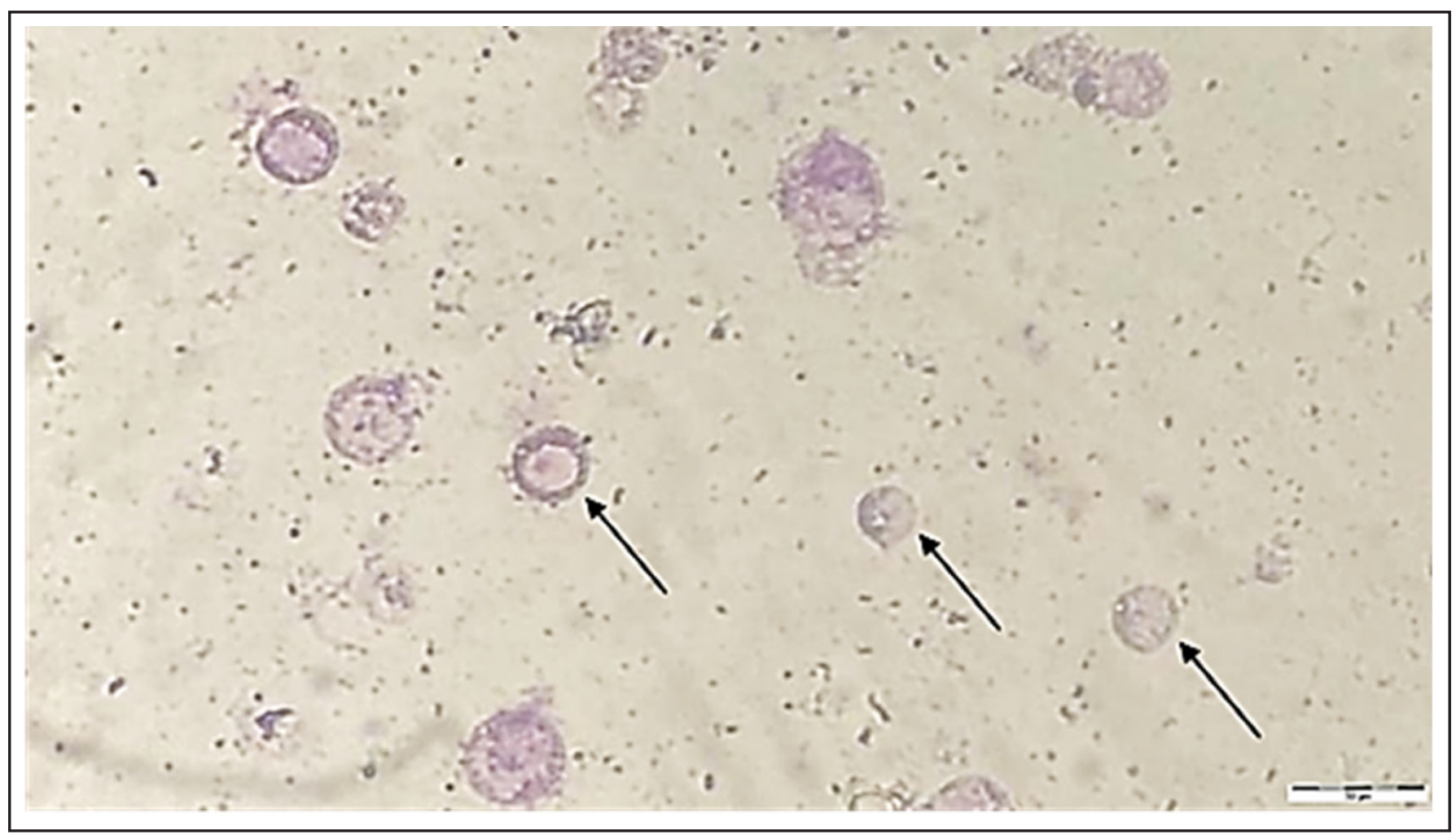

Figure 1. Vacuolar form of Blastocystis sp. in turkey (arrows).

$20 \mu \mathrm{m}$ in diameter (Figure 1). The granular forms size ranges from 5 to $30 \mathrm{im}$ in diameter and it was commonly found in the older cultures of isolates (Figure 2).

\section{Mode of reproduction}

The morphology of the Blastocystis sp. and different modes of reproduction was observed under light microscopy in the in vitro cultures. Nevertheless, the mode of reproduction commonly observed in this study was binary fission (Figure 3).

\section{Ultrastructure and surface structure}

Scanning electron micrographs showed the surface structure of Blastocystis sp. isolated from the selected faecal culture of closed house (B7c) and free-range (FM11) turkeys. The cell surface for both isolates were generally spherical to rounded in shape and had a rough surface coat with undulating cell surface whereas some organisms showed gouges or deep furrows (Figure 4).

Blastocystis cell isolated from the selected faecal culture of closed house (B7C) and free-range (FM11) turkeys were examined by using transmission electron microscopic. It was revealed that Blastocystis cells from the close house turkey isolate showed a central vacuole with partially expanded electron-opaque vacuoles (Figure 5a) whereas Blastocystis cells from the free-range turkey isolate contained a large central vacuole with tiny electron-dense particles in fully distended vacuoles (Figure 5b). Besides, the organisms also possessed a thin wispy surface coat that resembles a slight ruffled appearance of the surface observed under the scanning electron microscope.

\section{Subtype identification, alignment and phylogenetic analysis}

According to the sequence analysis of 30 positive Blastocystis isolates, one genotypes and three allele were identified by BLAST queries at Blastocystis Sequence Typing Database (https://www.publmst.org/blastocystis): ST7 allele 99 (73.4\%, $n=22)$, ST7 allele $100(23.3 \%, n=7)$ and ST7 allele $101(3.3 \%$, $n=1)$.

In closed house rearing system, allele 99 was the most common allele found with the frequency of $60.0 \%(6 / 10)$, followed by allele 100 with $30.0 \%$ (3/10), and allele 101 with $10.0 \%(1 / 10)$. Meanwhile in free range rearing system, allele 99 was also the most common allele with the frequency of $80.0 \%$ (16/20), followed by allele 100 with 20.0\% (4/20) and none was found for allele 101 in free range turkey rearing system (Figure 6).

Based on the allele distribution in sex of turkey, allele 99 was commonly found in male turkey with the frequency of $54.5 \%(12 / 15)$, followed by allele 100 with the frequency of $42.9 \%(3 / 15)$. In female turkey, it was found that allele 99 was the most common allele with the frequency of $57.1 \%(10 / 15)$, followed by allele 100 with $45.5 \%$ (4/15) and allele 101 with $10 \%(1 / 15)$.

The Maximum-likelihood ( $\mathrm{ML}$ ) phylogenetic tree was built to examine the positions of our new sequences against a selection of GenBank reference sequences. It was found that all the sequences obtained form a single clade as indicated in Figure 6.

\section{DISCUSSION}

In Malaysia, the broiler chicken, jungle fowl, village chicken and duck are available in numerous places as well as the cost is more affordable than the turkey meat. Turkey meat is typically sold at the average of RM25 to RM30 (Mohammad Zarith et al., 2017) per $\mathrm{kg}$ whereas chicken meat is approximately cost for about RM6 to RM10 per kg. In certain countries, market demand for turkey meat is less popular than chicken or even duck meat (Parrott \& Walley, 2017). Turkey meat consumption is scarcer particularly in Malaysia rather than the western countries namely, Canada and United States 


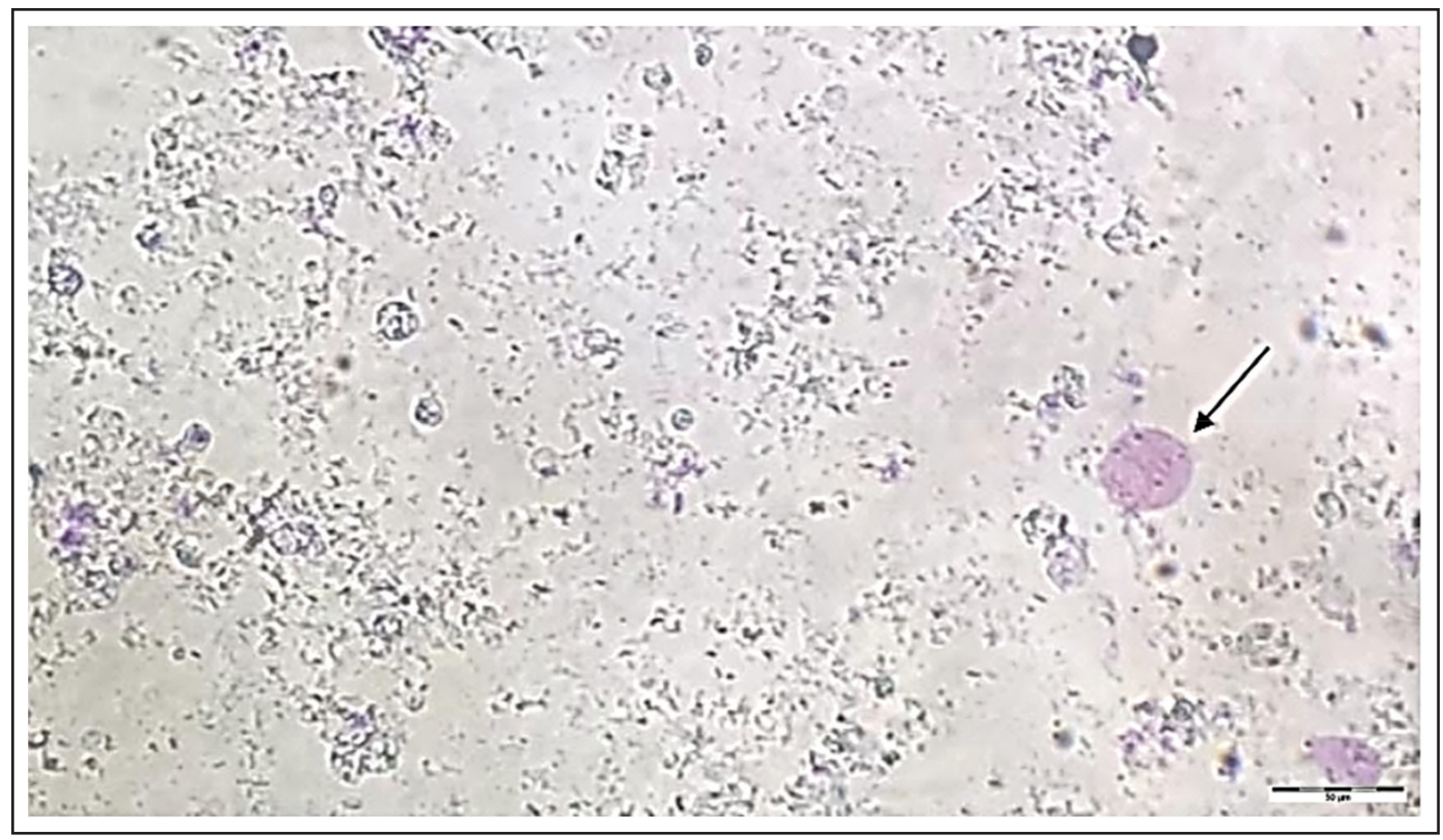

Figure 2. Granular form of Blastocystis sp. in turkey (arrow).

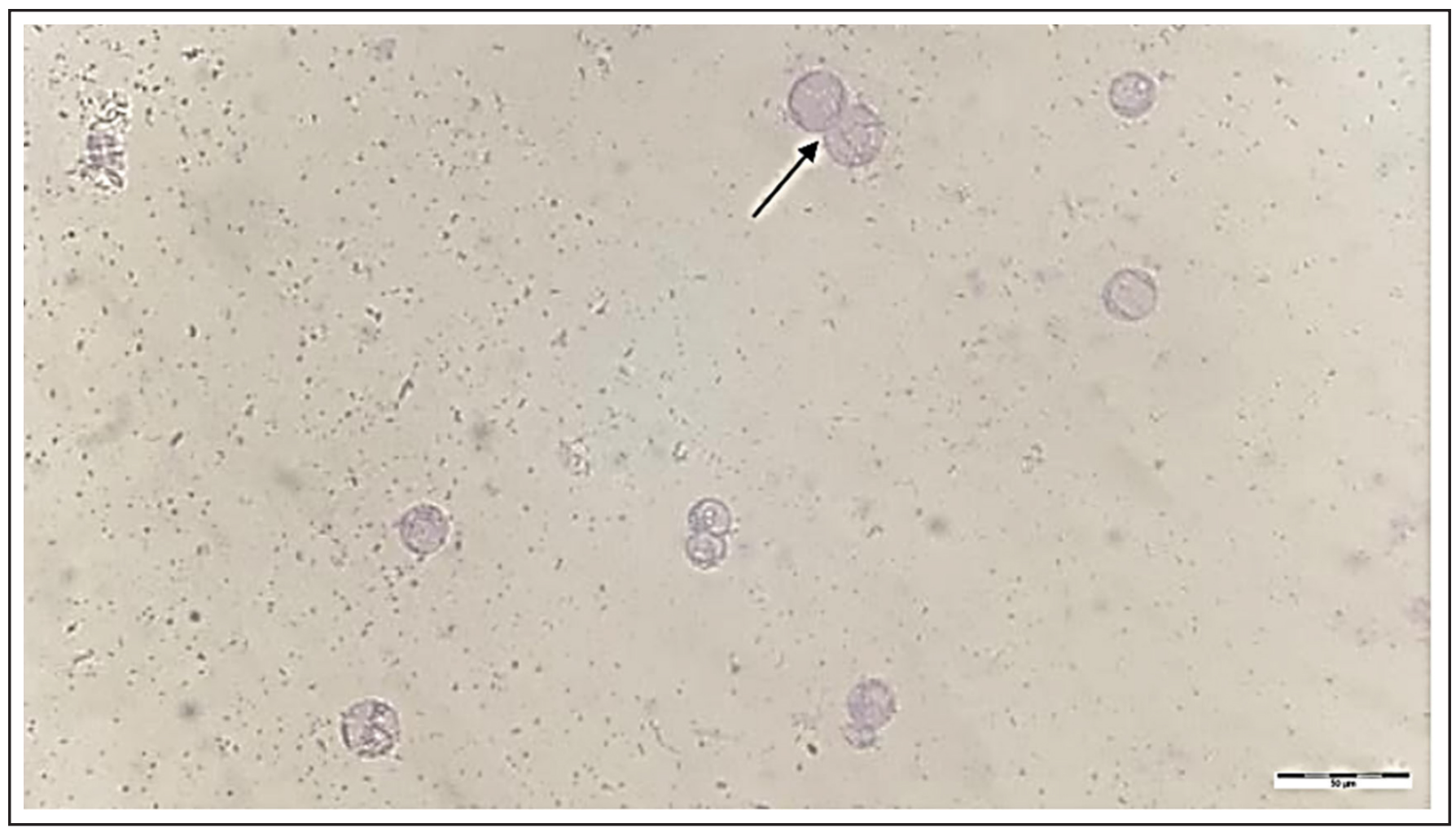

Figure 3. Binary fission, the reproduction mode of Blastocystis sp. (arrow) observed in turkey. 

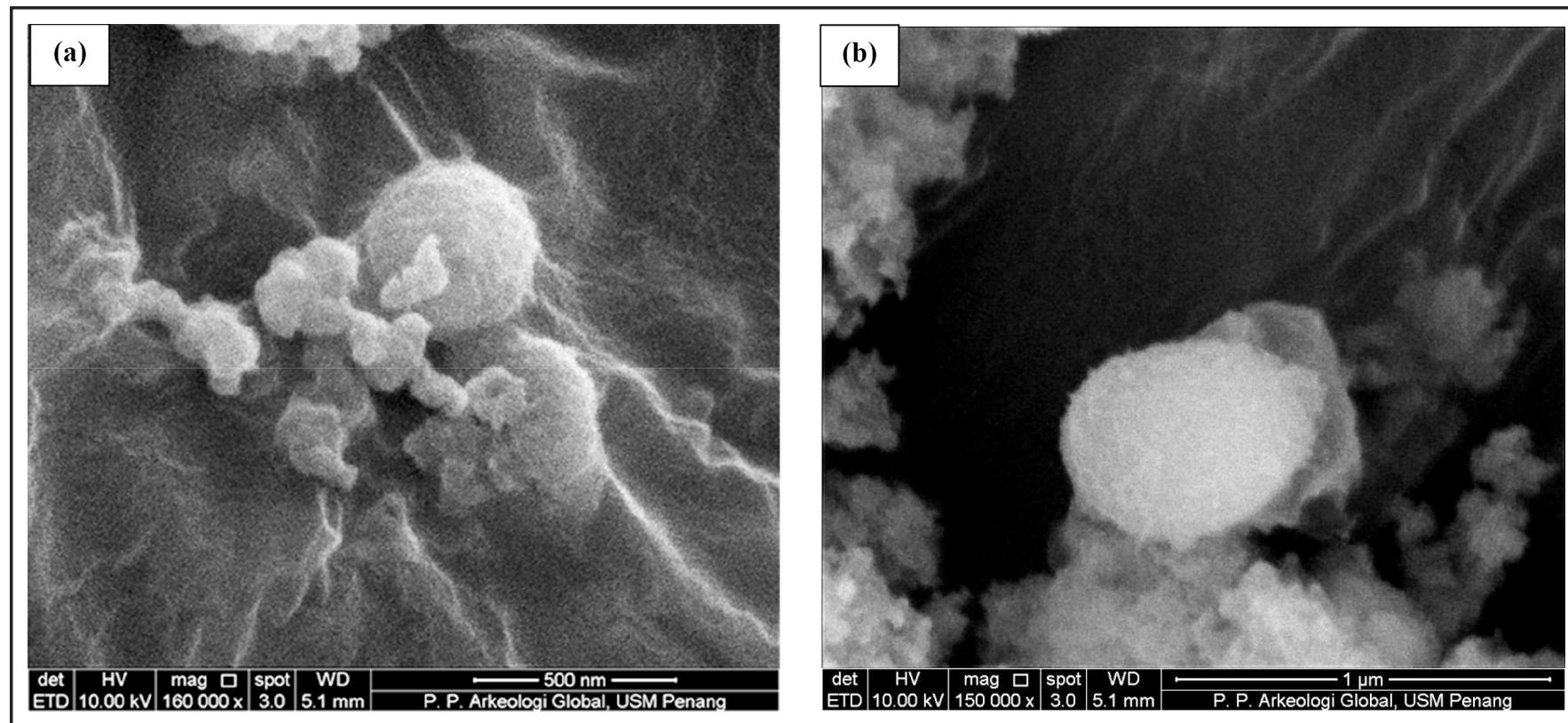

Figure 4. Surface structure of Blastocystis sp. (a) closed house turkey (B7c). (b) free-range turkey (FM11).
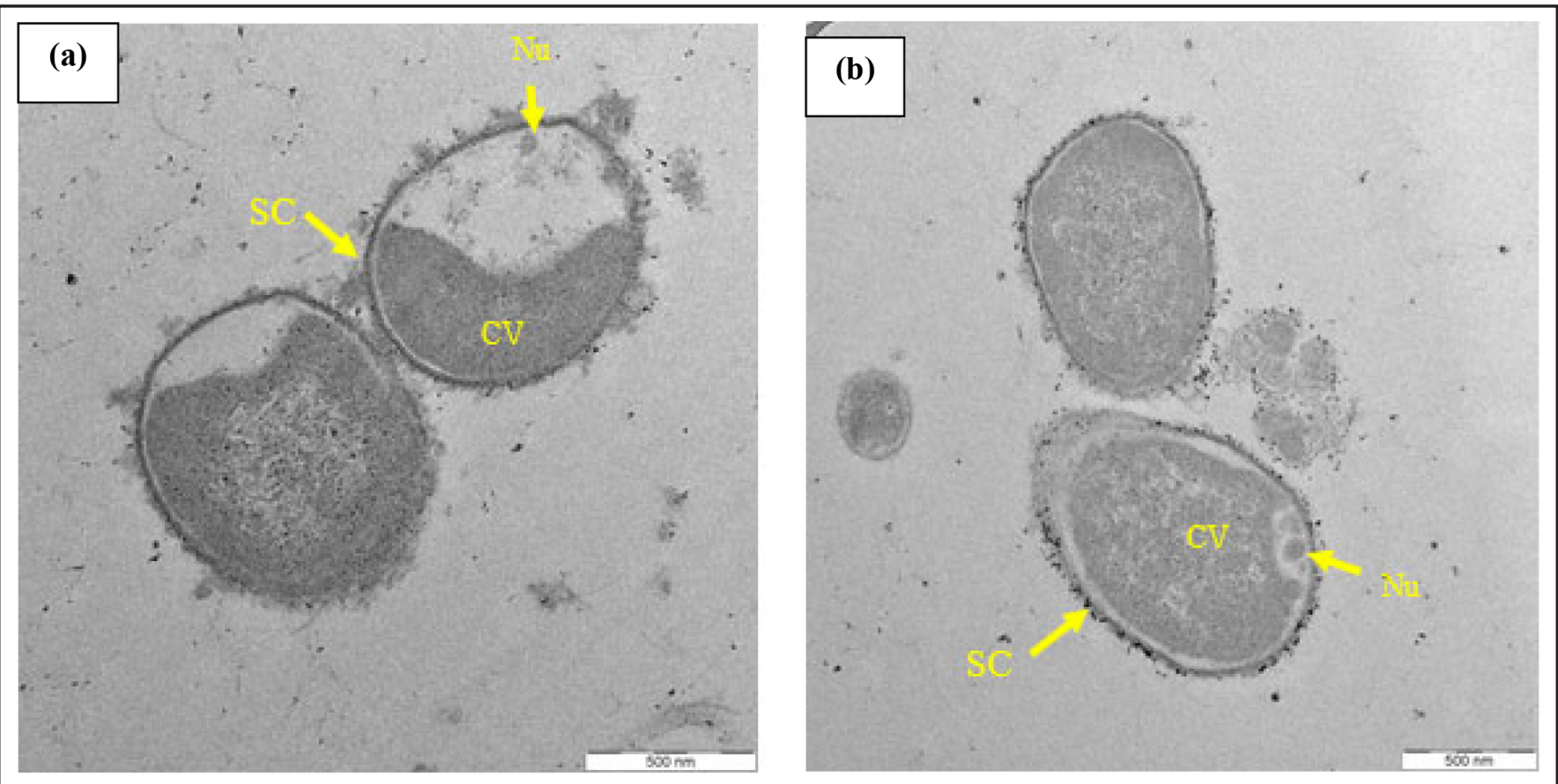

Figure 5. Transmission electron micrograph of Blastocystis sp. (a) closed house turkey (B7c) (b) free-range turkey (FM11). Nu; Nucleus, CV; Central Vacuole and SC; Surface Coat.

(Abduljaleel et al., 2012). Generally, cooking and eating turkey meat is associated with several festivities. In America and many parts of Europe, turkey meat will be served for dinner on Christmas Eve and the Thanksgiving Day. However, in Malaysia not only during Christmas Eve, turkey meat will also be being served during Diwali as a fascinating dish known as turkey biryani (Jayaraman et al., 2013).

Turkey population are not frequently been studied probably because they are less economically important to the poultry industry in Malaysia as compared to chicken and duck (Yadav et al., 2021). The only study on parasitic infection in turkey population in Malaysia was conducted by Mohammad Zarith et al. (2017) who reported on the occurrence of endo- and ectoparasites infection in free-range turkey population from Kedah, Malaysia. However, no attempt was made to detect the occurrence of the neglected zoonotic protozoan parasite, Blastocystis sp. infection in the turkey examined.

Studies on Blastocystis sp. infection was widespread and abundant in the animal population particularly in poultry, the avian population (Lee, 1970; Yamada et al., 1987; Belova \& Kostenko, 1990; Pakandl \& Pecka, 1992; Belova, 1992a, 1992b; 


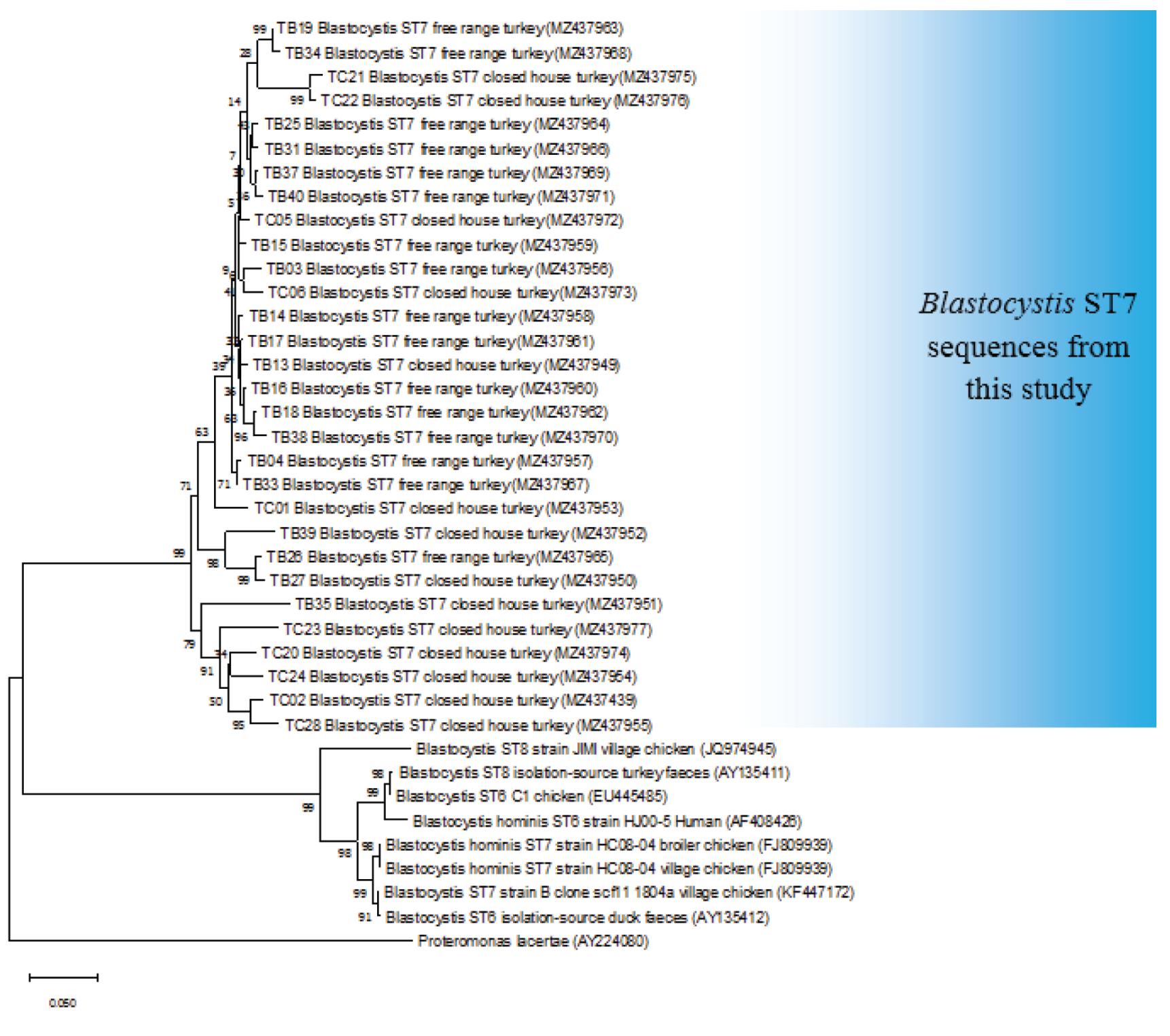

Figure 6. Phylogenetic tree of the new Blastocystis sp. sequences from turkey in Penang and reference SSU-rRNA gene sequences from GenBank.

Yoshikawa et al., 2003; Tanizaki et al., 2005; Stensvold et al., 2007; Tan, 2008; Clark et al., 2013; Adao \& Rivera, 2018; Farah Haziqah et al., 2018; Greige et al., 2018; AbuOdeh et al., 2019; Mohammadpour et al., 2020; Oliveira-Arbex et al., 2020; Boutellis et al., 2021). Similarly, in Malaysia most studies were mainly focusing on Blastocystis infection in chicken population as they are the largest poultry production in the farming system in Malaysia (Farah Haziqah et al., 2018). To date, there are no known study on Blastocystis sp. infection in turkey (Meleagris gallapavo) population in Malaysia.

Therefore, this study was conducted to determine the current status of Blastocystis infection in turkey population in the Northern region in Peninsular Malaysia particularly in Penang, Malaysia as commercial turkey farming was currently increased at the mainland of Penang due to the support and assistance by the DVS Penang. It was found that the prevalence of Blastocystis $\mathrm{sp}$. in turkey population was moderate with the prevalence of $43.8 \%$ (70/160) concurrent with Blastocystis infection in turkey from Egypt with 50\% (6/12) prevalence (Mokhtar \& Youssef, 2018). However, Sreekumar et al. (2014) reported high prevalence of infection in turkey from India with $70 \%(3 / 4)$.

Contrary to previous studies, this study examined a large number of turkeys with 160 animals were examined for Blastocystis infection with none of the positive turkeys showed behavioural signs or indication of infection. Apparently, other birds namely, ostriches infected with this protozoan parasite appeared healthy without any other symptoms as reported by Chandrasekaran et al. (2014). Currently, there is no conclusive evidence suggest the pathogenic role of Blastocystis infection in animals. However, Blastocystis may be a commensal organism that becomes pathogenic when the host is immunosuppressed, malnourished or has other source of infections such as bacterial or viral infection (Ginanjar et al., 2007; Lepczynska et al., 2016).

It was found that Blastocystis infection in free-range turkeys (45\%) were slightly higher than the closed house turkeys (41.6\%). Besides, based on the statistical analysis there was no significant different between different types 
of rearing system and the infection of Blastocystis. Infection among free-range turkey flock was most probably due to the scavenging habits. Thus, the possibility of ingesting the infective stage of Blastocystis sp. in the environment appears to be very high due to the soil floor system in the backyard barns which makes them more susceptible to Blastocystis infection. Although, the closed house turkeys were totally confined in barren windowless enclosed long house with a deep litter system, Blastocystis infection was also reported to be relatively high in the closed house turkeys due to unhygienic practices in the pens such as the infrequent of changing the sawdust material of the floor system.

Despite the turkeys were reared under a supervision of a veterinary health officer and were treated with antibiotic and anthelminthic medication, both the closed house and free-range turkey population were found to be infected with a high prevalence of Blastocystis. Thus, excellent hygiene and sanitation are vital in avoiding or reducing the infection of Blastocystis because it is the main contributor for the health maintenance of poultry management (Stenzel \& Boreham, 1996).

Finding from this study found that there was a significant difference between sex of turkey and Blastocystis infected. The prevalence of Blastocystis sp. infection in female turkeys were higher in both the free-range and closed house turkeys. The higher percentage of infection in the females may be due to the modification in the physiological condition of the animals during the production activity particularly during egg production in female turkeys as reported by Liu \& Bacon (2005). Besides, Lioyd (1983) also reported that the advanced level of prolactin and progesterone hormones make the female ruminant more susceptible to any infection. In contrary to a previous study by Azhar et al. (2002), there was no variation in gastrointestinal parasitic infection between the sex of host. The faecal smears with vacuolar and granular forms were stained with Giemsa Stain for confirmative analysis. The size of the Blastocystis forms encountered varied from 5 to $20 \mu \mathrm{m}$. The measurements of the vacuolar forms of Blastocystis sp. in chicken were quite varied, with a minimum measurement of $10 \mu \mathrm{m}$ and a maximum of $30 \mathrm{im}$ in diameter (Farah Haziqah et al., 2014). According to difference in size and shape, the organism is occasionally difficult to identify by wet mount preparation. Conferring to the study of Zaki et al. (1991), enduring smears seem to be the technique of choice for light microscopic analysis. The staining characteristic of Blastocystis with Giemsa is alike to that defined by Yamada \& Yoshikawa (2012) and Sreekumar et al. (2014) with the occurrence of an amorphous and granular substantial in the central vacuole and fluctuating number of nuclei (1-12) in the external rim of the cytoplasm. Morphological characteristics of Blastocystis in turkey isolates were observed. It was found that the most common form of Blastocystis in the in vitro culture was vacuolar. Moreover, granular form was commonly found in the older cultures of isolates.

Meanwhile, reproductive mode commonly observed in the in vitro culture of turkey faeces was binary fission which is characterised by the barrier of the cytoplasm of the mother cell and outcomes in two daughter cells with an identical size and shape. According to several studies on Blastocystis in poultry, there were two types of reproduction mode of the Blastocystis sp. been observed in poultry namely, binary fission and budding (Govind et al., 2002; Yamada \& Yoshikawa, 2012; Parija \& Jeremiah, 2013; Farah Haziqah et al., 2014).

The surface structure for both isolates of closed house and free-range turkeys were generally spherical to rounded in shape and had a rough surface coat with undulating cell surface whereas some organisms showed gouges or deep furrows similarly indicated in the isolates from diarrhea cattle (Widisuputri et al., 2021). Meanwhile, Cassidy et al. (1994) revealed that the surface structure of chicken isolates appeared to be compact with a smooth and undulating cell surface. It is apparent that the surface structures of Blastocystis sp. from different hosts are variable, and this study notes the surface structure morphology in turkeys as none was reported previously in this bird. Moreover, surface coat may absent in certain forms namely, in the avacuolar form and the amoeboid form from human isolates as reported by Dunn et al. (1989) and Stenzel et al. (1991). It has also been suggested that the features of the surface structure of Blastocystis sp. maybe correlated with symptomatic appearance (Widisuputri et al., 2021).

Studies on the ultrastructure of Blastocystis $\mathrm{sp}$. in poultry from Malaysia were previously reported in chickens (Farah Haziqah et al., 2018) and ostriches (Chandrasekaran et al., 2014). This study represented the ultrastructural features of Blastocystis vacuolar form isolated from the close house turkey isolate with a central vacuole contained partially expanded electron-opaque whereas Blastocystis cells from the freerange turkey isolate contained a large central vacuole with tiny electron-dense particles in fully distended vacuoles similarly reported in the barn-reared chicken (Farah Haziqah et al., 2018) and ostrich (Chandrasekaran et al., 2014) cells. Moreover, the ultrastructure features of Blastocystis in turkey was first demonstrated by Lee (1970) who also reported on the occurrence of finely granular material and crystalline inclusion in the central vacuole of the isolated Blastocystis cells. According to Yoshikawa et al. (1995), the dark electrondense particles seen in the central vacuole indicating the presence of lipid. Therefore, it can be confirmed that Blastocystis sp. from turkey, chicken as well as the ostrich isolates uses the vacuolar forms to store lipids due to the poultry diets which contains high-fat pellets (Loar \& Corzo, 2011; Evans et al., 2015).

There are very limited studies on subtype characterization of Blastocystis sp. isolated from turkeys (Noel et al., 2003; Mokhtar \& Youssef, 2018). Blastocystis ST6 was reported in the turkey isolates from France (Noel et al., 2003) whereas variety of subtypes was isolated from turkey population in Egypt namely, ST1, ST6 and ST7 (Mokhtar \& Youssef, 2018). Blastocystis ST1 was previously detected in variety of animal hosts namely, in chickens (Cian et al., 2017), dogs (Wang et al., 2013), pigs (Valenca-Barbosa et al., 2019), chimpanzees (Roberts et al., 2013), and gorillas (Roberts et al., 2013) as well as humans (Greige et al., 2018). Meanwhile, ST6 and ST7 were previously known as avian subtypes mainly because of its high prevalence in poultry specifically chickens, quails, geese as well as other bird population (Mokhtar \& Youssef, 2018). However, ST6 and ST7 is scarce in humans with the prevalence as low as $1 \%$ infection of Blastocystis ST6 in the Netherlands (Bart et al., 2013), 3.6\% infection of Blastocystis ST6 in Thailand (Jantermtor et al., 2013) and 1\% infection of Blastocystis ST7 from the American continent (Jiménez et al., 2019).

From this study, ST7 was the only subtypes detected from 30 positive isolates with three different alleles namely, allele 99, 100 and 101. Interestingly, ST7 allele 99 was not only found in turkey, it was also been reported in other domestic animals namely, dogs $(n=3)$ (Mohammadpour et al., 2020) and chicken ( $n=1)$ from Iran Rahimi et al. (2021). Notably, humans were also found to be infected with ST7 allele 99 as reported in a patient with Clostridium difficile infection (CDI) from Singapore (Deng et al., 2021) and one isolate from patient with diabetes mellitus in Brazil (Melo et al., 2020). Meanwhile, the only available data present to date for ST7 alleles 110 was by Lhotská et al. (2020) reported 
the occurrence of this subtype in the gut-healthy humans from Czech Republic and Deng et al. (2021) reported in one of the patients with CDI from Singapore. As for ST7 allele 101, one isolate was reported from patients with CDI Deng et al. (2021) with $100 \%$ identity to those in humans in the Czech Republic (Lhotská et al., 2020). Since these subtypes were previously reported in human populations, animals may serve as reservoir hosts and facilitate transmission to human. Therefore, it can be suggested that transmission may occur between domestic animals to animals or humans.

In this Maximum-likelihood phylogenetic tree, the sequence of Blastocystis generated from this study form a well-supported because Bootstrap proportion and a long branch propagation to monophyletic group. This clade is the sister group of all GenBank sequence. There are low intersequences within this clade variability because sequences are very similar to one another due to same origin of the species. However, these sequences are quite distinct from their sister group sequences.

\section{CONCLUSION}

In this study, it was found that despite being raised in an intensive closed house system, treated with antibiotic and anthelminthic medication under a supervision of veterinary health officer, high prevalence of Blastocystis infection was observed in the closed house turkey population. It can be concluded that establishment with high-quality hygiene and sanitary conditions might result in negative infection as good hygiene practices will contribute to better health maintenance of the birds. Although, these studies have assisted in understanding the morphological characterization of this protozoan parasite in turkey, the morphological characteristics were in accord with the general features of Blastocystis in other bird hosts namely, chickens. Besides, this study has generated a great deal of data on subtype of Blastocystis isolated from turkeys in which zoonotic subtype, ST7 (allele 99, 100 and 101) were identified out of 30 positives isolates from turkey. Thus, zoonotic transmission should be taken into consideration as the animal handlers particularly, turkey farmers or the slaughter workers might have high risk of infection as they are in constant contact with the birds and more susceptible to Blastocystis sp. infection. To date, there is no information on Blastocystis infection in turkey population Malaysia, thus the findings of this study added to our understanding on Blastocystis infection as this is the first study to evaluate the current status, morphology, ultrastructure and genetic characteristics of Blastocystis sp. isolated from free-range and close house turkeys in Malaysia.

\section{ACKNOWLEDGEMENTS}

The authors would like to thank Universiti Sains Malaysia (Short Term Grant 2018: 304/PBIOLOGI/6315156) and USM Postgraduate Research Grant Scheme (Siti Alawiyah: 1001. PBIOLOGI.AUPS001) for funding this study. A special thanks to all the staffs at Poultry Unit, Department of Veterinary Services, Penang state and the team from Veterinary Parasitology Laboratory USM for providing tremendous support and assistance on this study.

\section{Conflict of interest}

The authors declare that they have no conflict of interest.

\section{REFERENCES}

Abduljaleel, S.A., Shuhaimi-othman, M. \& Babji, A. (2012). Assessment of trace metals contents in chicken (Gallus gallus domesticus) and quail (Coturnix coturnix japonica) tissues from Selangor (Malaysia). Journal of Environment Science and Technology 1: 441-451. https://doi.org/10.3923/ jest.2012.441.451

AbuOdeh, R., Ezzedine, S., Madkour, M., Stensvold, C.R., Samie, A., Nasrallah, G., AlAbsi, E. \& ElBakri, A. (2019). Molecular subtyping of Blastocystis from diverse animals in the United Arab Emirates. Protist 170: 125679. https://doi.org/ 10.1016/j.protis.2019.125679

Adao, D.E.V. \& Rivera, W.L. (2018). Recent advances in Blastocystis sp. research. Philippine Science Letters 11: 39-60.

Alfellani, M.A., Jacob, A.S., Perea, N.O., Krecek, R.C., TanerMulla, D., Verweij, J.J., Levecke, B., Tannich, E., Clark, C.G. \& Stensvold, C.R. (2013). Diversity and distribution of Blastocystis sp. subtypes in non-human primates. Parasitology 140: 966-971.

Azhar, M., Chaudhry, S.H., Tanveer, A. \& Haji, A.H. (2002). Epidemiology of fasciolosis in buffaloes under different managemental conditions. Veterinarski Arhiv 72: 221-228. https://doi.org/10.3329/jbau.v9i1.8752

Bart, A., Wentink-Bonnema, E.M.S., Gilis, H., Verhaar, N., Wassenaar, C.J.A., Van Vugt, M., Goorhuis, A. \& Van Gool, T. (2013). Diagnosis and subtype analysis of Blastocystis sp. in 442 patients in a hospital setting in the Netherlands. BMC Infectious Diseases 13: 389. https://doi.org/10.1186/ 1471-2334-13-389

Belova, L.M. (1992a). On the occurrence of Blastocystis galli (Rhizopoda, Lobosea) in turkey. Parazitologiial 26: 5-10.

Belova, L.M. (1992b). A new species of Blastocystis anseri (Protista: Rhizopoda) from domestic geese. Parazitologiia 26: 80-82.

Belova, L.M. \& Kostenko, L.A. (1990). Blastocystis galli sp. n. (Protista: Rhizopoda) from the intestine of domestic hens. Parazitologiia 24: 164-168.

Boutellis, A., Aissi, M., Harhoura, K., Drali, R., Kernif, T. \& Tazerouti, F. (2021). First molecular characterization of Blastocystis subtypes from animals and animal-keepers stool in Algeria. Comparative Immunology, Microbiology and Infectious Diseases 78: 1-6. https://doi.org/10.1016/ j.cimid.2021.101695

Cassidy, M.F., Stenzel, D.J. \& Boreham, P.F.L. (1994). Electron microscopy of surface structures of Blastocystis sp. from different hosts. Parasitology 80: 505-511. https://doi.org/ 10.1007/BF00932698

Cathey, J.C., Melton, K., Dreibelbis, J., Cavney, B., Locke, S.L., DeMaso, S.J., Schwertner, T.W. \& Collier, B. (2007). Rio Grande wild turkey in Texas: biology and management. Texas Farmer Collection. https://doi.org/1969.1/87484

Chandrasekaran, H., Govind, S.K., Panchadcharam, C., Bathmanaban, P., Raman, K. \& Thergarajan, G. (2014). High lipid storage in vacoular forms of subtype 6 Blastocystis sp. in ostrich. Parasites and Vectors 7: 469-475. https:// doi.org/10.1186/s13071-014-0469-7

Cian, A., Safadi, D.E., Osman, M., Moriniere, R., Gantois, N., Benamrouz-Vanneste, S., Delgado-Viscogliosi, P., Guyot, K., Li, L., Monchy, S. et al. (2017). Molecular epidemiology of Blastocystis sp. in various animal groups from two French zoos and evaluation of potential zoonotic risk. PLOS ONE 12: e0169659. https://doi.org/10.1371/journal.pone. 0169659 
Clark, C.G. (1997). Extensive genetic diversity in Blastocystis hominis. Molecular Biochemical Parasitology 87: 79-83.

Clark, C.G., Alfellani, M., van der Giezen, M. \& Stensvold, C.R. (2013). Recent developments in Blastocystis research. Advances in Parasitology 82: 1-32. https://doi.org/10.1016/ B978-0-12-407706-5.00001-0

Deng, L., Chai, Y., Zhou, Z., Liu, H., Zhong, Z., Hu, Y., Fu, H., Yue, C. \& Peng, G. (2019). Epidemiology of Blastocystis sp. infection in China: a systematic review. Parasite 26: 41-50. https://doi.org/10.1051/parasite/2019042

Deng, L., Yao, J., Chen, S., He, T., Chai, Y., Zhou, Z., Shi, X., Liu, H., Zhong, Z., Fu, H. et al. (2021). First identification and molecular subtyping of Blastocystis sp. in zoo animals in southwestern China. Parasites and Vectors 14: 1-11. https://doi.org/10.1186/s13071-020-04515-2

Dornyei, Z. (2007). Research methods in applied linguistics: Quantitative, qualitative, and mixed methodologies. New York: Oxford University Press, pp. 336.

Dunn, L.A., Boreham, P.F. \& Stenzel D.J. (1989). Ultrastructural variation of Blastocystis hominis stocks in culture. International Journal for Parasitology 19: 43-56. https:// doi.org/10.1016/0020-7519(89)90020-9

Etikan, I., Musa, S.A. \& Alkassim, R.S. (2016). Comparison of convenience sampling and purposive sampling. American Journal of Theoretical and Applied Statistics 5: 1-4. https:// doi.org/10.11648/j.ajtas.20160501.11

Evans, A.M., Loop, S.A. \& Moritz, J.S. (2015). Effect of poultry litter biochar diet inclusion on feed manufacture and 4to 21-d broiler performance. Poultry Science Association 24: 380-386. https://doi.org/10.3382/japr/pfv039

Fahim, S.M., Gazi, M.A., Hasan, M.M., Alam, M.A., Das, S., Mahfuz, M., Rahman, M.M., Haque, R., Sarker, S.A. \& Ahmed, T. (2021). Infection with Blastocystis spp. and its association with enteric infections and environmental enteric dysfunction among slum-dwelling malnourished adults in Bangladesh. PLoS Neglected Tropical Diseases 15: e0009684. https://doi.org/10.1371/journal.pntd.0009684

Farah Haziqah, M.T., Chandrawathani, P., Mohd Zain, S.N., Suresh Kumar, G., Hemalatha, C., Mohd \& Premaalatha, B. (2014). A preliminary study of Blastocystis sp. isolated from chicken in Perak and Selangor, Malaysia. Malaysian Journal of Veterinary Research 5: 21-25.

Farah Haziqah, M.T., Chandrawathani, P., Suresh, K.G., Wilson, J., Mohd Khairul Nizam, M.K., Arutchelvan, R.A., Premaalatha, B. \& Siti Nursheena, M.Z. (2018). Prevalence, ultrastructure and subtypes of Blastocystis in chickens (Gallus Gallus) from Peninsular Malaysia. Southeast Asian Journal of Tropical Medicine and Public Health 49: 921-932.

Gentekaki, E., Curtis, B.A., Stairs, C.W., Klimeš, V., Eliáš, M., Salas-Leiva, D.E., Herman, E.K., Eme, L., Arias, M.C., Henrissat, B. et al. (2017). Extreme genome diversity in the hyper-prevalent parasitic eukaryote Blastocystis. PLoS Biology 15: e2003769. https://doi.org/10.1371/journal.pbio. 2003769

Ginanjar, E., Kurniawan, A., Hardjono, T., Syam, A.F. \& Pitoyo, W. (2007). Diagnosis and management of Blastocystis hominis infection in patient with HIV/AIDS. The Indonesian Journal of Gastroenterology, Hepatology, and Digestive Endoscopy 8: 57-62. https://dx.doi.org/10.24871/8220075762

Govind, S.K., Khairul, A.A., Smith, H.V. (2002). Multiple reproductive processes in Blastocystis. Trends in Parasitology 18: 528-529. https://doi.org/10.1016/s1471-4922(02)02402-9
Greige, S., El Safadi, D., Bécu, N., Gantois, N., Pereira, B., Chabé, M., BenamrouzVanneste, S., Certad, G., El Hage, R., Chemaly, M. et al. (2018). Prevalence and subtype distribution of Blastocystis sp. isolates from poultry in Lebanon and evidence of zoonotic potential. Parasites and Vectors 11: 389. https://doi.org/10.1186/s13071-0182975-5

Hauck, R. \& Hafez, H.M. (2012). Experimental infections with the protozoan parasite Histomonas meleagridis: a review. Parasitology Research 112: 19-34. https://doi.org/10.1007/ s00436-012-3190-5

Jantermtor, S., Pinlaor, P., Sawadpanich, K., Pinlaor, S., Sangka, A., Wilaoluckana, C., Wongsena, W. \& Yoshikawa, H. (2013). Subtype identification of Blastocystis spp. isolated from patients in a major hospital in northeastern Thailand. Parasitology Research 112: 1781-1786. https://doi.org/ 10.1007/s00436-012-3218-x

Jayaraman, K., Munira, H., Chowdhury, D. \& Iranmanesh, M. (2013). The preference and consumption of chicken lovers with race as a moderator - An empirical study in Malaysia. International Food Research Journal 20: 165-174.

Jiménez, P.A., Jaimes, J.E. \& Ramírez, J.D. (2019). A summary of Blastocystis subtypes in North and South America. Parasites and Vectors 12: 376-384. https://doi.org/10.1186/s13071-0193641-2

Kumar, S., Stecher, G., Li, M., Knyaz, C. \& Tamura, K. (2018). MEGA X: Molecular Evolutionary Genetics Analysis across computing platforms. Molecular Biology and Evolution 35: 1547-1549. https://doi.org/10.1093/molbev/msy096

Lee, D.L. (1970). The fine structure of Blastocystis from the caecum of turkey. Transactions of the British Mycological Society 54: 313-317.

Lepczyñska, M., Chen, W.C. \& Dzika, E. (2016). Mysterious chronic urticaria caused by Blastocystis spp. International Journal of Dermatology 55: 259-266. https://doi.org/10.1111/ ijd.13064

Lhotská, Z., Jirku, M., Hlo•ková, O., Bro•ová, K., Jirsová, D., Stensvold, C.R., Kolisko, M. \& Pomajbíková, K.J. (2020). A study on the prevalence and subtype diversity of the intestinal protist Blastocystis sp. in a gut-healthy human population in the Czech Republic. Frontiers in Cellular and Infection Microbiology 10: 544335. https://doi.org/10.3389/ fcimb. 2020.544335

Lioyd, S. (1983). Effect of pregnancy and lactation up on infection. Veterinary Immunology and Immunopathology 4: 153-176. https://doi.org/10.1016/0165-2427(83)90057-0

Liu, H.K. \& Bacon, W.L. (2005). Changes in egg production rate induced by progesterone injection in broiler breeder hens. Poultry Science 84: 321-327. https://doi.org/10.1093/ ps/84.2.321

Loar, R.E. \& Corzo, A. (2011). Effects of feed formulation on feed manufacturing and pellet quality characteristics of poultry diets. World's Poultry Science Journal 67: 19-28. https://doi.org/10.1017/S004393391100002X

Maloney, J.G. \& Santin, M. (2021). Mind the gap: New fulllength sequences of Blastocystis subtypes generated via oxford nanopore nanopore minion sequencing allow for comparisons between full-length and partial sequences of the small subunit of the ribosomal RNA gene. Microorganisms, 9: 997-1017. https://doi.org/10.3390/microorganisms9050997 
Maloney, J.G., Da Cunha, M.J.R., Molokin, A., Cury, M.C. \& Santin, M. (2021). Next-generation sequencing reveals wide genetic diversity of Blastocystis subtypes in chickens including potentially zoonotic subtypes. Parasitology Research 120: 2219-2231. https://doi.org/10.1007/s00436021-07170-3

Maloney, J.G., Molokin, A., Da Cunha, M.J.R., Cury, M.C. \& Santin, M. (2020). Blastocystis subtype distribution in domestic and captive wild bird species from Brazil using next generation amplicon sequencing. Parasite Epidemiology and Control 9: 1-9. https://doi.org/10.1016/j.parepi.2020. e00138

Melo, G.B., Roldan, W., de Mello Malta, F., Lescano, S.A.Z., Castilho, V.L., do Nascimento Goncalves, E.M., de Paula, F.M. \& Gryschek, R.C.B. (2020). Culture isolation and molecular identification of Blastocystis sp. in Brazilian human isolates: preliminary results. Journal of the São Paulo Institute of Tropical Medicine 62: 51-55. https://doi.org/ 10.1590/S1678-9946202062051

Miller, J.E. (2018). Wild Turkeys. Wildlife Damage Management Technical Series. USDA, APHIS, WS National Wildlife Research Center. Fort Collins, Colorado. pp. 12.

Mohammad Zarith, Z., Suhaila, A.H., Nik Ahmad Irwan Izzauddin, N.H. \& Khadijah, S. (2017). Parasites prevalence in poultry: focusing on free range turkeys (Meleagris gallopavo). Malaysian Journal of Veterinary Research 8: 1-9.

Mohammadpour, I., Bozorg-Ghalati, F., Gazzonis, A.L., Manfredi, M.T., Motazedian, M.H. \& Mohammadpour, N. (2020). First molecular subtyping and phylogeny of Blastocystis sp. isolated from domestic and synanthropic animals (dogs, cats and brown rats) in Southern Iran. Parasites and Vectors 13: 365-375. https://doi.org/10.1186/ s13071-020-04225-9

Mokhtar, A. \& Youssef, A. (2018). Subtype analysis of Blastocystis spp. isolated from domestic mammals and poultry and its relation to transmission to their in-contact humans in Ismailia governorate, Egypt. Parasitologists United Journal 11: 90-98. https://doi.org/10.21608/PUJ.2018.16318

Noël, C., Peyronnet, C., Gerbod, D., Edgcomb, V.P., DelgadoViscogliosi, P., Sogin, M.L., Capron, M., Viscogliosi, E. \& Zenner, L. (2003). Phylogenetic analysis of Blastocystis isolates from different hosts based on the comparison of small-subunit rRNA gene sequences. Molecular Biochemical Parasitology 126: 119-123. https://doi.org/10.1016/ s0166-6851(02)00246-3

Oliveira-Arbex, A.P., David, E.B., da Silva Tenorio, M., Pyles Cicchi, P.J., Patti, M., Coradi, S.T., Lucheis, S.B., Jim, J. \& Guimarães, S. (2020). Diversity of Blastocystis subtypes in wild mammals from a zoo and two conservation units in southeastern Brazil. Infection, Genetics and Evolution 78: 16. https://doi.org/10.1016/j.meegid.2019.104053

Pakandl, M. \& Pecka, Z. (1992). A domestic duck as a new host for Blastocystis sp. Folia Parasitologica 39: 59-60.

Parija, S.C. \& Jeremiah, S. (2013). Blastocystis: Taxonomy, biology and virulence. Tropical Parasitology 3: 17-25. https://doi.org/ 10.4103/2229-5070.113894

Parrot, P. \& Walley, K. (2017). Consumer attitudes to poultry meat: A comparative study of the UK and China. In: Woodhead Publishing Series in Food Science, Technology and Nutrition. Petracci, M. \& Berri, C. (editors). Woodhead Publishing, pp. 313-334. https://doi.org/10.1016/B978-0-08100763-1.00013-1
Rahimi, H.M., Mirjalali, H. \& Zali, M.R. (2021). Molecular epidemiology and genotype/subtype distribution of Blastocystis sp., Enterocytozoon bieneusi, and Encephalitozoon spp. in livestock: concern for emerging zoonotic infections. Scientific Reports 11: 17467. https://doi.org/10.1038/s41598021-96960-x

Ramírez, J.D., Sánchez, L.V., Bautista, D.C., Corredor, A.F., Flórez, A.C. \& Stensvold, C.R. (2014). Blastocystis subtypes detected in humans and animals from Colombia. Infection, Genetics and Evaluation 22: 223-228. https://doi.org/10.1016/ j.meegid.2013.07.020

Rauff-Adedotun, A.A., Mohd Zain, S.N. \& Farah Haziqah, M.T. (2020). Current status of Blastocystis sp. in animals from Southeast Asia: a review. Parasitology Research 119: 35593570. https://doi.org/10.1007/s00436-020-06828-8

Roberts, T., Stark, D., Harkness, J. \& Ellis, J. (2013). Subtype distribution of Blastocystis isolates from a variety of animals from New South Wales, Australia. Veterinary Parasitology 196: 85-89. https://doi.org/10.1016/j.vetpar. 2013.01.011

Rudziñska, M., Kowalewska, B., Waleron, M., Kalicki, M., Sikorska, K. \& Szostakowska, B. (2021). Molecular characterization of Blastocystis from animals and their caregivers at the Gdañsk zoo (Poland) and the assessment of zoonotic transmission. Journal of Biology 10: 984-1002. https://doi.org/10.3390/biology10100984

Sharman, P.A., Smith, N.C., Wallach, M.G. \& Katrib, M. (2010). Chasing the golden egg: vaccination against poultry coccidiosis. Parasite Immunology 32: 590-598. https:// doi.org/10.1111/j.1365-3024.2010.01209.x

Sreekumar, C., Selvaraj, J., Gomathinayagam, S., Thangapandiyan, M., Ravikumar, G., Roy, P. \& Balachandran, C. (2014). Blastocystis sp. from food animals in India. Journal of Parasitic Diseases 38: 440-443. https://doi.org/ 10.1007/s12639-013-0236-2

Stensvold, C.R. \& Clark, C.G. (2020). Pre-empting Pandora's box: Blastocystis subtypes revisited. Trends in Parasitology 36: 229-232. https://doi.org/10.1016/j.pt.2019.12.009

Stensvold, C.R., Alfellani, M.A., Nørskov-Lauritsen, S., Prip, K., Victory, E.L., Maddox, C., Nielsen, H.V. \& Clark, C.G. (2009). Subtype distribution of Blastocystis isolates from synanthropic and zoo animals and identification of a new subtype. International Journal for Parasitology 39: 473479. https://doi.org/10.1016/j.ijpara.2008.07.006

Stensvold, C.R., Lebbad, M., Hansen, A., Beser, J., Belkesa, S., Andersen, L.O. \& Clark, C.G. (2020). Differentiation of Blastocystis and parasitic archamoebids encountered in untreated wastewater samples by amplicon-based nextgeneration sequencing. Parasite Epidemiology and Control 9: e00131. https://doi.org/10.1016/j.parepi.2019.e00131

Stensvold, C.R., Suresh, G.K., Tan, K.S., Thompson, R.C., Traub, R.J., Viscogliosi, E., Yoshikawa, H. \& Clark, C.G. (2007). Terminology for Blastocystis subtypes - a consensus. Trends in Parasitology 23: 93-96. https://doi.org/10.1016/j.pt.2007. 01.004

Stenzel, D.J., Boreham, P.F.L. \& McDougall, R. (1991). Ultrastructure of Blastocystis hominis in human stool samples. International Journal for Parasitology 21: 807-812. https:// doi.org/10.1016/0020-7519(91)90149-2

Stenzel, D.J. \& Boreham, P.F. (1996). Blastocystis hominis revisited. Clinical Microbiology Reviews 9: 563-584. https:// doi.org/10.1128/CMR.9.4.563 
Tamura, K. (1992). Estimation of the number of nucleotide substitutions when there are strong transitiontransversion and G + C-content biases. Molecular Biology and Evolution 9: 678-687. https://doi.org/10.1093/ oxfordjournals.molbev.a040752

Tan, K.S.W. (2008). New insights on classification, identification, and clinical relevance of Blastocystis spp. Clinical Microbiology Reviews 21: 639-665. https://doi.org/10.1128/ CMR.00022-08

Tanizaki, A., Yoshikawa, H., Iwatani, S. \& Kimata, I. (2005). Infectivity of Blastocystis isolates from chickens, quails and geese in chickens. Parasitology Research 96: 57-61. https://doi.org/10.1007/s00436-005-1326-6

Valença-Barbosa, C., do Bomfim, T.C.B., Teixeira, B.R., Gentile, R., Neto, S.F.D.C., Magalhães, B.S.N., Balthazar, D.A., da Silva, F.A., Biot, R., d'Avila Levy, C.M. et al. (2019). Molecular epidemiology of Blastocystis isolated from animals in the state of Rio de Janeiro, Brazil. PLoS One 14: e0210740. https:/ /doi.org/10.1371/journal.pone.0210740

Wang, W., Cuttell, L., Bielefeldt-Ohmann, H., Inpankaew, T., Owen, H. \& Traub, R.J. (2013). Diversity of Blastocystis subtypes in dogs in different geographical settings. Parasites and Vectors 6: 215. https://doi.org/10.1186/17563305-6-215

Wang, J., Gong, B., Liu, X., Zhao, W., Bu, T., Zhang, W., Liu, A. \& Yang, F. (2018). Distribution and genetic diversity of Blastocystis subtypes in various mammal and bird species in northeastern China. Parasites and Vectors 11: 552. https:/ /doi.org/10.1186/s13071-018-3106-z

Widisuputri, N.K.A., Lastuti, N.D.R., Suprihati, E., Hastutiek, P., Plumeriastuti, H., Mufasirin, Puspitasari, H. \& Suwanti, L.T. (2021). Surface ultrastructure of Blastocystis sp. isolated from cattle. Journal of Biological Diversity 22: 1514-1518. https://doi.org/10.13057/biodiv/d220356
Yadav, J.P., Tomar, P., Singh, Y., Khurana, S.K. (2021). Insights on Mycoplasma gallisepticum and Mycoplasma synoviae infection in poultry: a systematic review. Animal Biotechnology 10: 110. https://doi.org/10.1080/10495398.2021.1908316

Yamada, M. \& Yoshikawa, H. (2012). Morphology of human and animal Blastocystis isolates with special reference to reproductive modes. In: Blastocystis: Pathogen or Passenger? Mehlhorn H., Tan K. \& Yoshikawa H. (editors). Berlin, Heidelberg: Springer, pp. 9-35.

Yamada, M., Yoshikawa, H., Tegoshi, T., Matsumoto, Y., Yoshikawa, T., Shiota, T. \& Yoshida, Y. (1987). Light microscopical study of Blastocystis spp. in monkeys and fowls. Parasitology Research 73: 527-531. https://doi.org/10.1007/ BF00535328

Yoshikawa, H., Satoh, J. \& Enose, Y. (1995). Light and electron microscopic localization of lipids in Blastocystis hominis. Journal of Electron Microscopy (Tokyo) 44: 100-103. https:// doi.org/10.1093/oxfordjournals.jmicro.a051148

Yoshikawa, H., Wu, Z., Nagano, I. \& Takahashi, Y. (2003). Molecular comparative studies among Blastocystis isolates obtained from humans and animals. Journal of Parasitology 89: 585-594. https://doi.org/10.1645/00223395(2003)089[0585:MCSABI]2.0.CO;2

Zaki, M., Daoud, A.S., Pugh, R.N.H., Al-Ali, F., Al-Mutairi, G. \& Al-Saleh, Q. (1991). Clinical report of Blastocystis hominis infection in children. Journal of Tropical Medical Hygiene 94: 118-122.

Zhang, K., Zheng, S., Wang, Y., Wang, K., Wang, Y., Gazizova, A., Han, K., Yu, F., Chen, Y. \& Zhang, L. (2021). Occurrence and molecular characterization of Cryptosporidium spp., Giardia duodenalis, Enterocytozoon bieneusi, and Blastocystis sp. in captive wild animals in zoos in Henan, China. BMC Veterinary Research 17: 332-340. https://doi.org/10.1186/ s12917-021-03035-0 